\begin{tabular}{|c|}
\hline 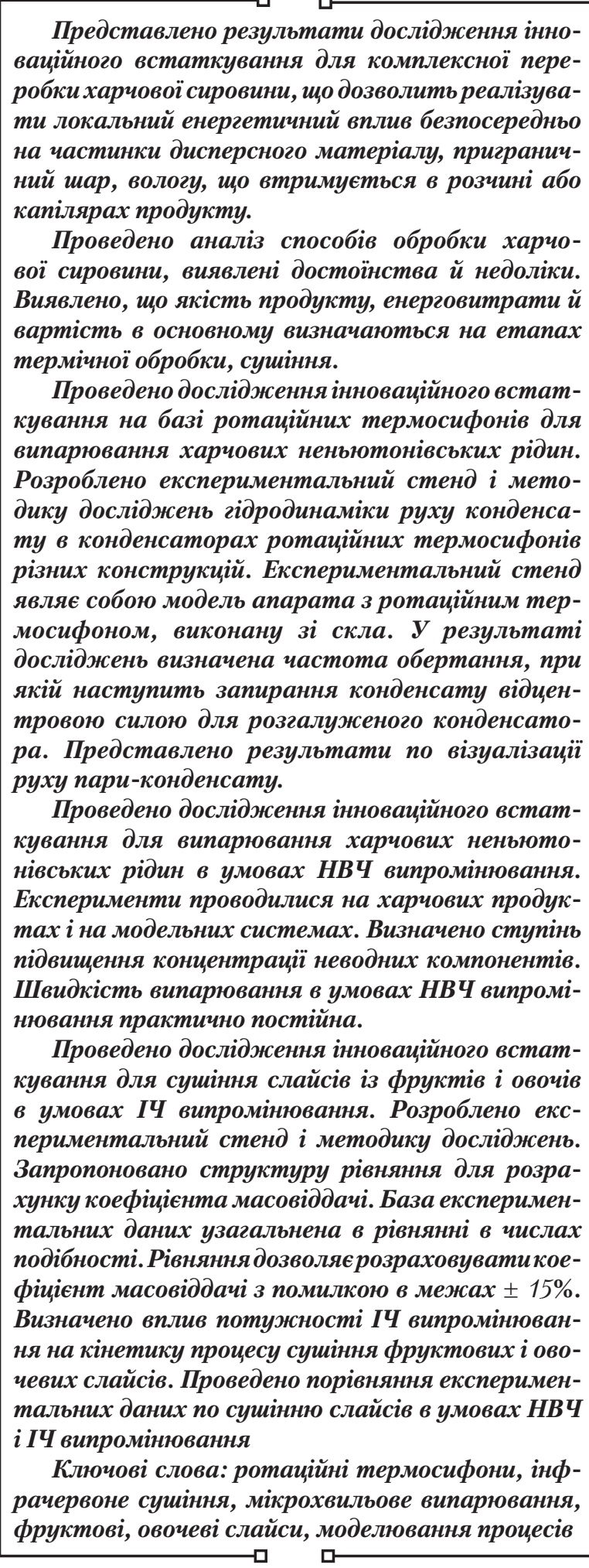 \\
\hline
\end{tabular}

Received date 25.07.2019

Accepted date 17.09.2019

Published date 24.10.2019
UDC 664.87.036.021.3.4

DOI: $10.15587 / 1729-4061.2019 .178937$

\section{STUDYING THE OPERATION OF INNOVATIVE EQUIPMENT FOR THERMOMECHANICAL TREATMENT AND DEHYDRATION OF FOOD RAW MATERIALS}

\author{
O. B u r d o
}

Doctor of Technical Sciences, Professor*

I. B e z b a h

Doctor of Technical Sciences, Associate Professor*

E-mail: igorbezbakh1003@gmail.com

N. Ke p in

$\mathrm{PhD}$, Associate Professor*

A. Z y k o v

Doctor of Technical Sciences*

I. Yarovy i

PhD, Associate Professor*

A. Gavrilov

$\mathrm{PhD}$, Associate Professor

Department of Technology and Equipment Production and

Processing of Livestock Products

Academy of Bioresources and Environmental Management

«V. I. Vernadsky Crimean Federal University»

Naukova str., 1, Agrarnoe vill., Simferopol,

Republic of Crimea, 295492

V. B a n d u r a

$\mathrm{PhD}$, Professor

Department of Technological Processes and Equipment

Processing and Food Production

Vinnytsia National Agrarian University

Sonyachna, str., 3, Vinnytsia, Ukraine, 21008

I. Mazurenko

Doctor of Technical Sciences, Vice-Rector for Scientific Work

Odessa State Agrarian University

Panteleimonivska str., 13, Odessa, Ukraine, 65012

*Department of Processes, Equipment and

Energy Management

Odessa National Academy of Food Technologies

Kanatna str., 112, Odessa, Ukraine, 65039

Copyright (C) 2019, O. Burdo, I. Bezbah, N. Kepin, A. Zykov,

I. Yarovyi, A. Gavrilov, V. Bandura, I. Mazurenko

This is an open access article under the CC BY license (http://creativecommons.org/licenses/by/4.0)

\section{Introduction}

Principal stages in the technological process of plant raw materials processing are the processes of heat processing, evaporation, and drying.
The efficiency of technologies is defined in terms of product kinetics, energy intensity, and quality. The kinetic parameter of drying is the intensity of dehydration, the rate of drying, which is expressed in $\mathrm{kg} / \mathrm{s}$ of removed moisture. Energy intensity is characterized by the amount of energy 
per a $\mathrm{kg}$ of removed moisture $(\mathrm{MJ} / \mathrm{kg})$. Correct assessment of these parameters is a serious task as the process of plant raw materials drying is a multifactorial dependence.

At food enterprises, the drying of plant raw materials is carried out by hot air or smoke gases at convective drying plants. The efficiency of convective dryers is $40 \%$. Energy costs of convective dryers reach $8 \mathrm{MJ} / \mathrm{kg}$ of removed moisture, which is almost three times larger than the physically required minimum. The content of carcinogens in a drying agent and a product is not controlled.

Energy costs for heat treatment, evaporation range from $2.8 \times 10^{6} \mathrm{~kJ}$ per $1 \mathrm{t}$ of evaporated water (a one-stage process) to $0,85 \times 10^{5} \mathrm{~kJ}$ per $1 \mathrm{t}$ (a multi-stage process). Fluids of the non-Newtonian group form in most cases in the process of evaporation. High energy costs related to their treatment necessitate finding new effective techniques and equipment.

The issue of improving quality of the finished product, energy intensity, environmental-friendliness of production [1-3], is a relevant task for food producers.

\section{Literature review and problem statement}

Heat treatment of various dispersed products and non-Newtonian liquids (NNL) employs heat exchangers with rotating surfaces, which include rotary heat exchangers and plants based on rotating thermal tubes (TTs) or rotating thermosyphons (RTS). Such structures make it possible to disrupt a border heat layer, which leads to the process intensification, decreases energy costs, and reduces fast burning of a product to the heating surface.

In order to properly design equipment of this class, it is necessary to take into consideration the external problem on calculating hydrodynamic conditions and heat-mass exchange when the heating surface is flown over with a liquid or air-dispersed flow, as well as the internal problem that takes into consideration the hydrodynamics of condensate movement inside the channels of the heating surface or condenser.

Papers $[4,5]$ address the external problem only. The internal problem was not solved by the authors. This might be due to that rotary heat exchangers are circulating; steam supply and condensate removal is organized at high pressures of the heat carrier $(0.3 \ldots 0.5 \mathrm{MPa})$ that provides for a stable internal heat exchange regardless of the rotation frequency. However, as regards rotational heat exchangers, sealing a connection node between the rotating rotor and a fixed steam pipe line and condensate line is technically challenging; and additional devices are needed to generate and supply steam.

Heat exchangers with TTs, RTSs have proven their advantages over conventional heat exchangers in many areas, such as waste heat disposal, waste treatment, alternative energy generation [8]. The development of modern technologies makes it possible to implement TTs and RTSs in the food industry. From a reliability point of view, these devices are more efficient because they are autonomous structures.

For devices with rotating TT, the internal problem is solved in [6,7], but it cannot be applied for RTS.

Paper [9] addresses the use of RTS for food technology devices. The internal and external problems on heat exchange for RTS have been simulated. The heat transmission crisis at RTS has been studied. A model has been obtained to determine the critical Froude number. However, issues about the experimental confirmation of the received model remained unresolved.
It is advisable to conduct a study on the visualization of hydrodynamics of condensate movement in the condensers of RTS of various structures, experimental confirmation of the developed model [9].

Microwave evaporating plants (MEPs) are used for food NNLs. Such designs effectively solve the problems associated with heat transmission in condensed solutions [10], but their production cannot be referred to as industrial while, up to now, generally recognized scientific theories and design techniques for such devices have not yet been devised.

Paper [10] reports results from an experimental study into the process of evaporating juice at MEP. It was shown that selective energy supply technologies are an effective tool for improving evaporating devices for juice concentration. However, issues related to the degree of concentration for various solutions (apple juice, milk, tomato paste) remained unresolved.

A study on the degree of concentration of solutions at MEP is appropriate.

There are technical solutions for drying wet materials using, as a source of energy supply, IR radiation [11-14]; such dryers provide for a high heat exchange coefficient, reducing the insemination of the product by microorganisms.

Authors of study [12] conducted a comparative analysis of the kinetics of drying, qualitative indicators for shitake mushrooms, dried with hot air drying, IR drying and intermittent drying with hot air using ultra-high-frequency (UHF) radiation. Intermittent UHF drying resulted in a significant reduction in drying time and higher drying speed compared with other methods. However, the cited work failed to address issued related to the mathematical model that describe the drying kinetics.

Article [13] examined the effect of combined IR vacuum drying on the drying kinetics, moisture diffusion factor, and the kinetics of color change in lemon slices. A model has been developed in the form of a regression equation, taking into consideration a change in the color of the product.

Paper [14] explored the IR drying of garlic slices in a thin layer at varying supplied power, radiation intensity and airflow speed. The results showed an increase in the rate of drying with a decrease in air flow speed and an increase in the intensity of IR radiation. A third-order polynomial equation was derived, relating the effective moisture diffusion factor and moisture content.

Papers [12-14] did not tackle issues related to drying the slices of apples, beets, potatoes, onions, carrots, pumpkins. In addition, the studies involving modeling $[13,14]$ applied regression models, polynomial equations. Application of such models does not make it possible to analyze the physical essence of the process, while experimental modeling necessitates taking into consideration a large number of parameters.

It is advisable to conduct a study into the kinetics of IR drying of slices of apples, beets, potatoes, onions, carrots, pumpkins. By analogy to [12], it is proposed to compare the results from IR and UHF drying of slices. In addition, it is necessary to develop a model, in similarity numbers, to calculate a mass transfer coefficient in the process of IR drying of slices.

\section{The aim and objectives of the study}

The aim of this work is to study the operation of innovative equipment for integrated processing of food raw 
materials, which would make it possible to implement a local energy impact directly on the particles of a dispersed material, the border layer, moisture contained in a solution or capillaries of the product. The result to be expected could improve products quality, as well as energy efficiency of production.

To accomplish the aim, the following tasks have been set:

- to perform experimental simulation of condensate movement inside an RTS;

- to conduct experimental study into the IR drying of fruit and vegetable slices, to summarize the data in the form of a model in similarity numbers;

- to compare experimental data on the IR and UHF drying of fruit and vegetable slices;

- to determine the degree to which the concentration of non-water components in MEP is increased.

\section{Materials and methods to study the operation of innovative equipment for integrated processing of food raw materials}

\section{1. Simulation of condensate movement inside a ro- tating thermosyphon}

The hydrodynamics of condensate flow inside the RTS branched condenser, given in [9], depends on the angle of inclination, rotation frequency of the RTS condenser. Analytical methods were used to define the function of the critical Froude number ( Fr $)$ for the RTS branched condenser. The aim is to experimentally confirm the analytical data obtained. To model the condensate movement inside an RTS condenser with various structural execution, we have designed an experimental bench (Fig. 1), which represents a model of the device with RTS made of glass. Ethyl alcohol was used as the RTS working body (volumetric share is $96 \%$, volume is $200 \mathrm{ml}$ ).

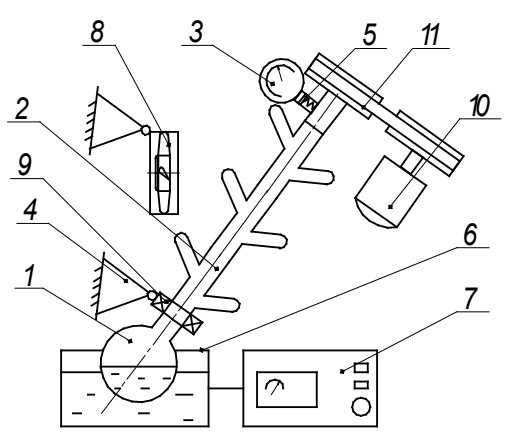

Fig. 1. Experimental bench to study the hydrodynamics of condensate movement inside the RTS condenser:

1 - RTS vaporizer, 2 - RTS condenser, 3 - pressure gauge, 4 - hinge, 5 - refueling valve, 6 - thermostat, 7 -regulator, 8 - fan, 9 - fluoroplastic bearing, 10 -drive, 11 - wedge-belt transmission

During experiments, we changed the RTS inclination angle $\gamma=20 \ldots 90^{\circ}$, the RTS rotation frequency, $n=0 \ldots 2 \mathrm{~s}^{-1}$, the vapor pressure inside the RTS, $P_{\mathrm{abs}}=0.1 \mathrm{MPa}$. We also replaced the RTS condenser from a branched to an auger one.

The use of an auger condenser provides for a series of advantages such as the stability of operation regardless of rotation frequency, stirring, mixing, transportation. The inclination angle and the direction of RTS rotation will determine the conditions for the return of condensate to the vaporizer. A series of experiments have been carried out to model the internal problem.

The research procedure is as follows. Air from the RTS was pumped out with a vacuum pump. We set a certain angle of the RTS inclination, the frequency of rotation. The thermostat regulator was used to set the voltage needed to maintain a stable boiling of the working body at a predefined pressure. We took photographs and recorded videos.

\section{2. Modelling the process of evaporating liquid prod-} ucts under conditions of microwave radiation

Analytical and physical modeling was carried out to study the operation of MEPs, to develop methods for calculating them and optimizing them. Experimental study for MEP were conducted at bench [10]. Information was acquired at a laptop or the tablet CHUWI CW1506. The developed software enabled the displaying of thermograms on the screen, moisture removal from the chamber, as well as the instantaneous values of moisture removal rate (\% per minute). Experiments were carried out using food products (juice, milk, tomato paste) and model systems (oak wood water, sand - water).

\section{3. Modelling the process of infrared drying}

Analytical and physical modeling was carried out to study the operation of IR dryers, to develop methods for calculating them and optimizing them. Based on the dimensional analysis method, the type of a criterion equation was established to calculate the magnitude of mass transfer coefficient $\beta$ for each input parameter. We have obtained the Sherwood $(S h)$ number dependence on the Burdo $(B u)$ number, the parametric complex $(H)$, which takes into consideration the effect of layer thickness, and the shape factor $(F)$ :

$$
S h=A \times B u^{n} \cdot H^{m} \cdot F^{k},
$$

where $S h$ - Sherwood number; $B u=N /(W r)$ - Burdo number; $H=\left(H_{i} / H_{0}\right)$ - parametric complex; $F=V /(f \delta)$ - shape factor; $r$ - hidden heat of vapor formation; $H_{i}$ - current magnitude of a layer; $H_{0}$ - basic thickness of a layer; $V$ - product volume; $f$ - product surface area; $\delta$ - characteristic size; $W$ - steam generating capacity.

Coefficients $A, n, m, k$ at the variables of equation 1 can be determined only experimentally. A series of experimental studies have been carried out to determine the key parameters of the design and the main nodes in the IR drying plant. An experimental drying unit has been set up to carry out physical simulation of the process of IR drying of various materials; its diagram is shown in Fig. 2. The bench consists of a fan, a drying chamber, an IR emitter. The design of the installation makes it possible to execute controlled and dosed influence on materials by IR radiation.

We studied the kinetics of drying of slices from fruits and vegetables. The experiments were carried out in the range of power of infrared radiation of $1.88 \ldots 11.25 \mathrm{~kW} / \mathrm{m}^{2}$. The product was cut into slices with a thickness of $0.003 \mathrm{~m}$ and with a radius of $0.025 \mathrm{~m}$. The weight of the cassette load was 50 grams. The experiments were carried out in a stationary layer, the mass $(\mathrm{m})$ of removed moisture was measured. Products with different properties were selected to study the effect of IR radiation on food raw materials: apples, beets, potatoes, pumpkin, onions, carrots. 
In fruit, vegetable raw materials, the most labile components are: $\beta$-carotene, vitamin $\mathrm{C}$, polyphenols. These parameters were selected as product quality indicators after drying.

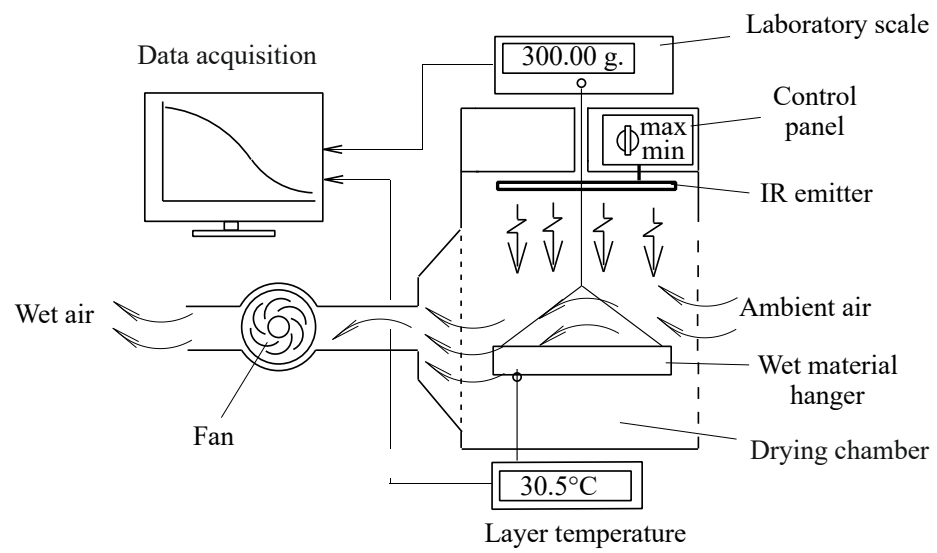

Fig. 2. Schematic of experimental bench for IR drying

The quality indicators of dry products were determined using standardized methods and procedures based on the following physical and chemical indicators:

- the mass share of moisture or dry substances - by the method that implies drying a loosened product sample or a sample distributed over the absorbing surface according to GOST 28561-90;

- the mass share of $\beta$-carotene - by the column chromatography method according to DSTU 4305:2004;

- the mass share of vitamin C - by a fluorometric method, according to GOST 24556-89;

- the mass share of polyphenols - by spectrophotometric or calorimetric method, according to DSTU 4373:2005.

\section{Results of studying the operation of innovative equipment for integrated processing of food raw materials}

\section{1. Results of experimental simulation of condensate} movement in a rotating thermosyphon

At the RTS inclination angles of $\gamma=0 \ldots 20^{\circ}$ the condensate accumulates in the lower branches of the condenser; the upper ones do not fill. Moreover, more condensation accumulates in the tubes closest to the vaporizer (Fig. 3).

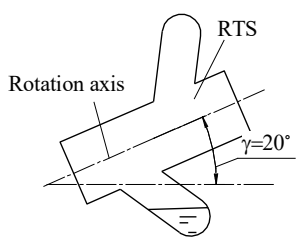

$a$

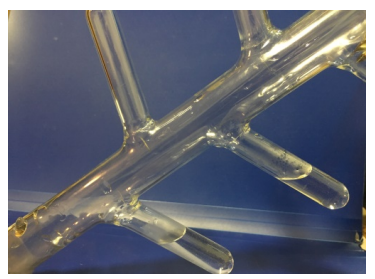

b
Fig. 3. Distribution of condensate in the branched RTS condenser, $n=0 \mathrm{~s}^{-1}, \gamma=20^{\circ}: a$-schematic; $b$-photograph

At rotational frequencies $n=0.1 \ldots 0.3 \mathrm{~s}^{-1}$, the condensate freely returns to the vaporizer, both at vertical position and at the tilt of the RTS. At rotation frequency $1.8 \mathrm{~s}^{-1}$ and a condenser's inclination angle $\gamma=20^{\circ}$, condensate is locked by a centrifugal force in the condenser branch pipes.
At inclination angle of the auger condenser $\gamma=37 \ldots 45^{\circ}$, erformance of the empty auger increases (Fig. 4).

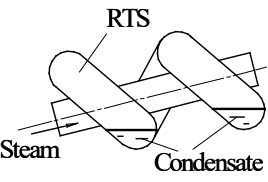

a

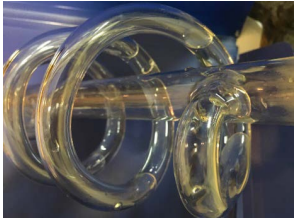

b

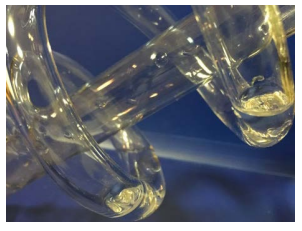

c
Fig. 4. Distribution of steam condensate in the condenser of an auger RTS, $n=0.1 \mathrm{~s}^{-1}, \gamma=20^{\circ}$ : $a$-schematic; $b, c$ - photographs

When the auger condenser rotates, there is an effective return of condensate to the vaporizer, both in right-hand rotation and in the left-hand direction of rotation. At right-hand rotation, condensate moves to the lower part of the condenser and is released into the central tube. At left-hand rotation condensate rises to the top of the condenser and is also released into the central tube, which is connected to the vaporizer.

5. 2. Results of experimental study of the infrared drying of fruit and vegetable slices

In the installation shown in Fig. 2, we experimentally determined effect of the power supplied on the drying kinetics of apple slices. At a power of $6 \mathrm{~kW} / \mathrm{m}^{2}$, the drying to a mass of $14 \mathrm{~g}$ was $2,150 \mathrm{~s}$ (Fig. 5). With a reduction in the power of IR radiation by 0.63 and 0.31 times, the process time increased by 1.28 and 2 times, respectively. With an increase in the supplied power of IR radiation by 1.46 and 1.88 times, the process time decreased by 1.33 and 1.82 times, respectively. Depending on the level of power supplied (Fig. 5), the time spent on drying to the required moisture content of $11-15 \%$ amounted to $1,100 \ldots 4,600 \mathrm{~s}$.

At the same time, our study of energy intensity of the drying process (Fig. 7) has revealed that more intensive drying regimes require greater energy costs.

The process of drying apple slices to the moisture content of $11-15 \%$ (Fig. 6) at a power of $1.88 \mathrm{~kW} / \mathrm{m}^{2}$ required $325 \mathrm{~kJ}$ of energy. The process lasted for $4,600 \mathrm{~s}$. At a power of $11.25 \mathrm{~kW} / \mathrm{m}^{2}, 490 \mathrm{~kJ}$ were spent. The duration of the process was $1,100 \mathrm{~s}$. Change in the power of IR emitters (Fig. 7) affected the drying speed in the range of $0.54 \ldots 2.5 \mathrm{~g} / \mathrm{min}$ of removed moisture. Constant drying rate is observed on average up to the moisture content of $18-22 \%$.

At a power of $1.88 \mathrm{~kW} / \mathrm{m}^{2}$, temperature (Fig. 8) did not exceed $58{ }^{\circ} \mathrm{C}$ even with a long-term treatment of raw materials.

For each product, the drying rate (Fig. 9) is constant to the moisture content of 20-23\% after which the drying rate slows down.

Temperatures (Fig. 10) for different kinds of vegetables and fruits have almost the same character of growth rate. 


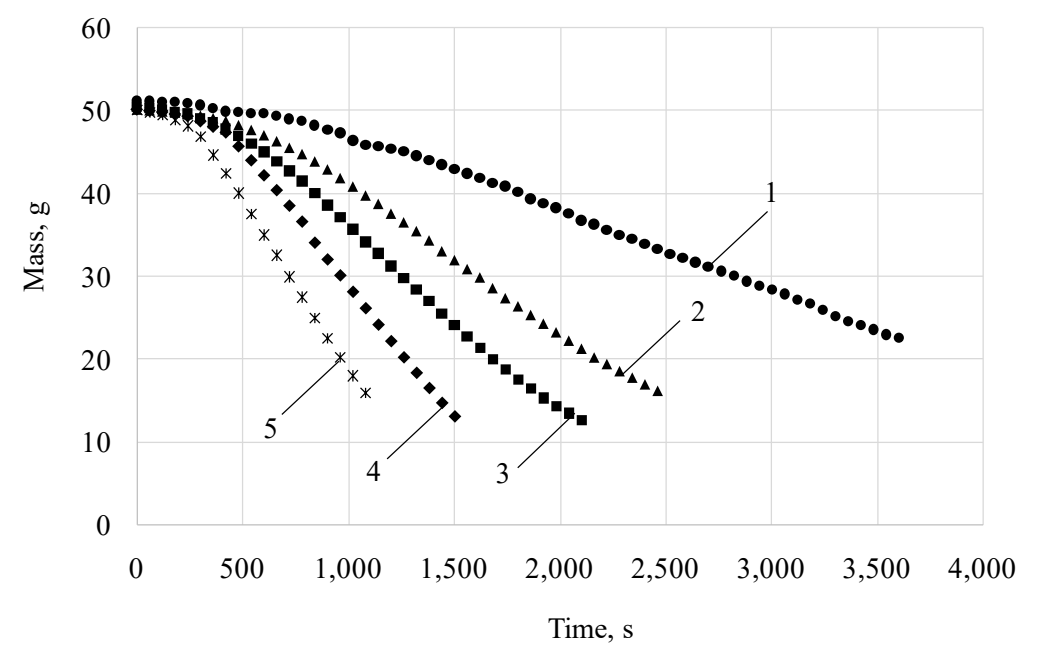

Fig. 5. Effect of IR radiation power on the drying kinetics of apple slices, where $N, \mathrm{~kW} / \mathrm{m}^{2}$ : $1-1.88 ; 2-3.75 ; 3-6 ; 4-8.75 ; 5-11.25$

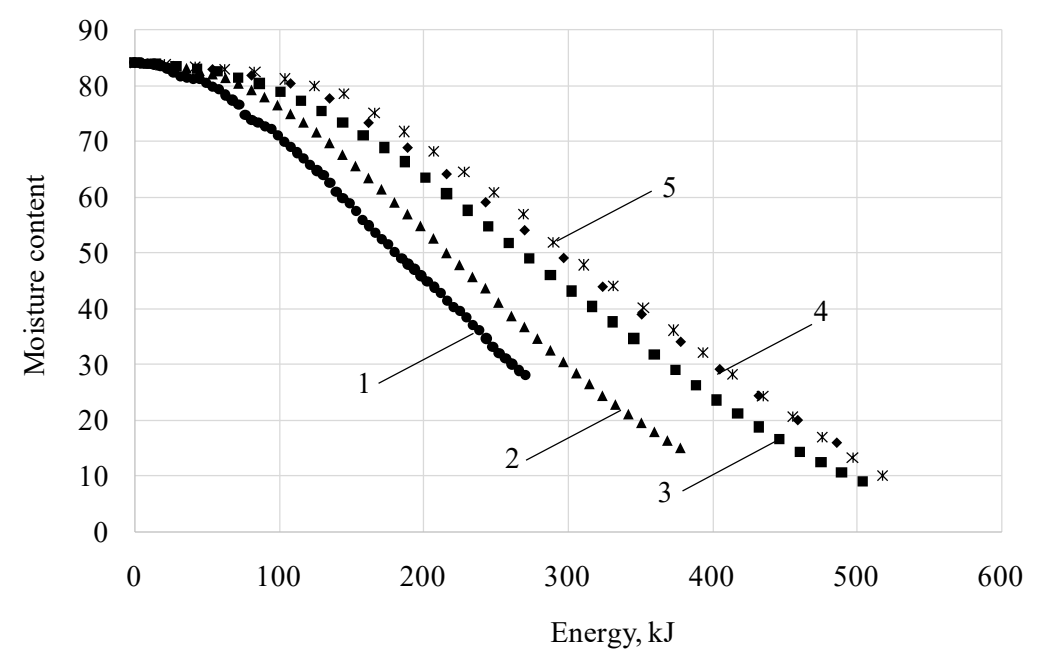

Fig. 6. Effect of IR radiation power on energy costs of the process of drying apple slices, where $N, \mathrm{~kW} / \mathrm{m}^{2}$ : $1-1.88 ; 2-3.75 ; 3-6 ; 4-8.75 ; 5-11.25$

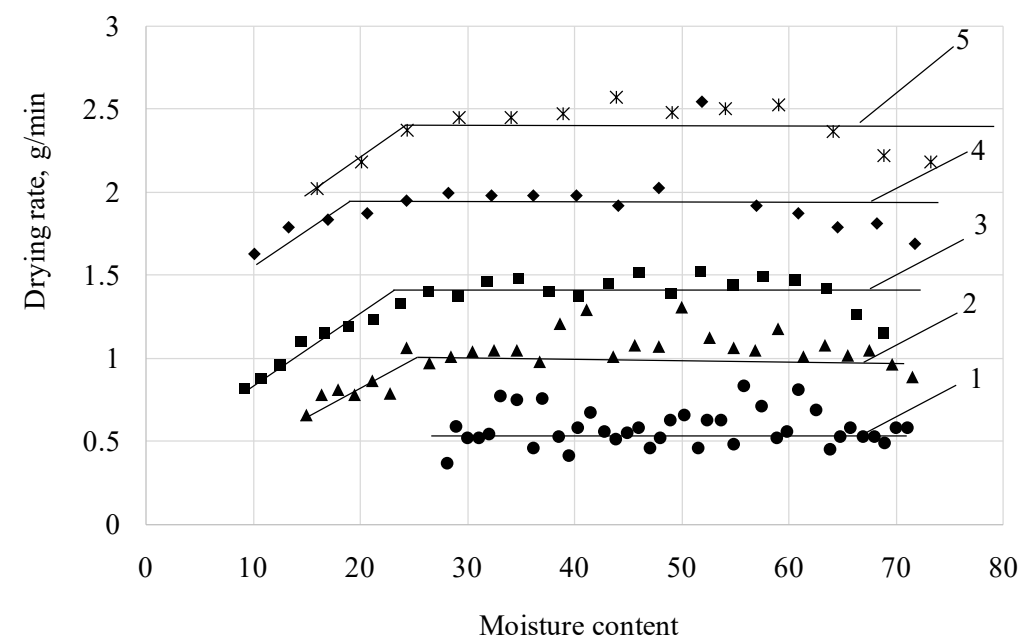

Fig. 7. Effect of the supplied power on the drying rate of apple slices, where $N, \mathrm{~kW} / \mathrm{m}^{2}$ :

$$
1-1.88 ; 2-3.75 ; 3-6 ; 4-8.75 ; 5-11.25
$$

The constants for equation (1) are derived by the method of linearizing the power function $S h=f(B u, H, F)$. We have obtained the dependence of Sherwood's number on Burdo number:

$$
S h=0,14 \cdot 10^{-10} B u^{1,9} H^{-1,28} F^{-0,0037} .
$$

Fig. 11 shows mathematical model (2) correlated with experimental data. 


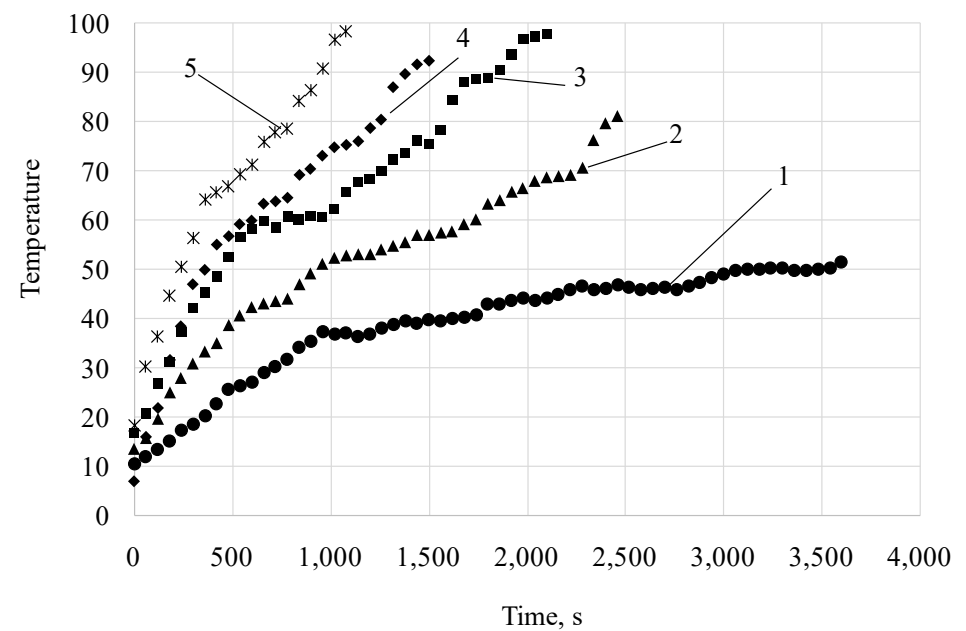

Fig. 8. Effect of IR radiation power on temperatures of apple slices, where $N, \mathrm{~kW} / \mathrm{m}^{2}$ : $1-1.88 ; 2-3.75 ; 3-6 ; 4-8.75 ; 5-11.25$

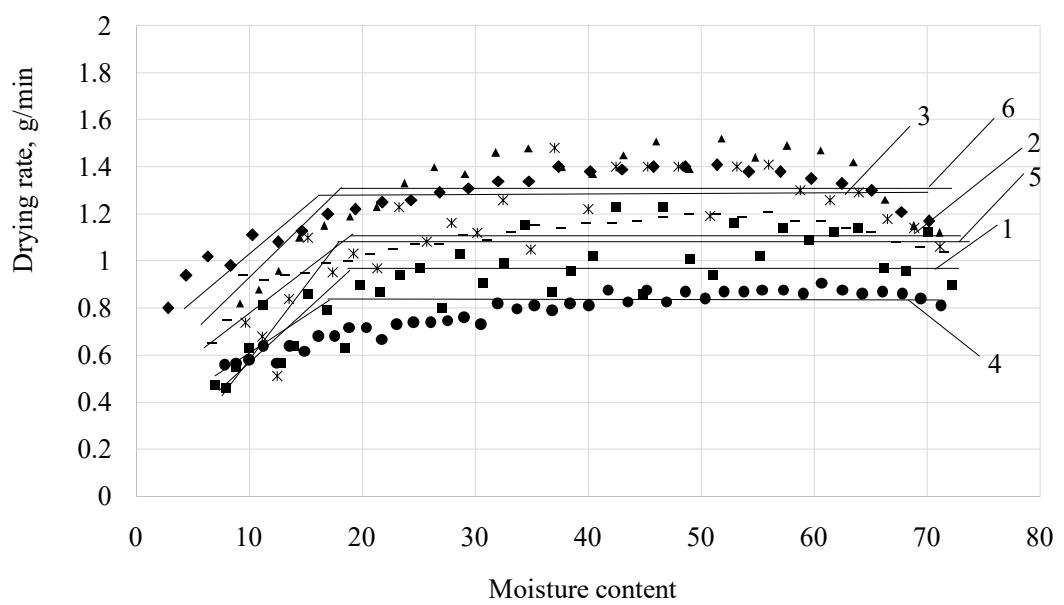

Fig. 9. Lines of drying rate for slices of fruits and vegetables, $N=8,75 \mathrm{~kW} / \mathrm{m}^{2}$ : 1 - beetroot; 2 - potatoes; 3 - pumpkin; 4 - onion; 5 - carrot; 6 -apple

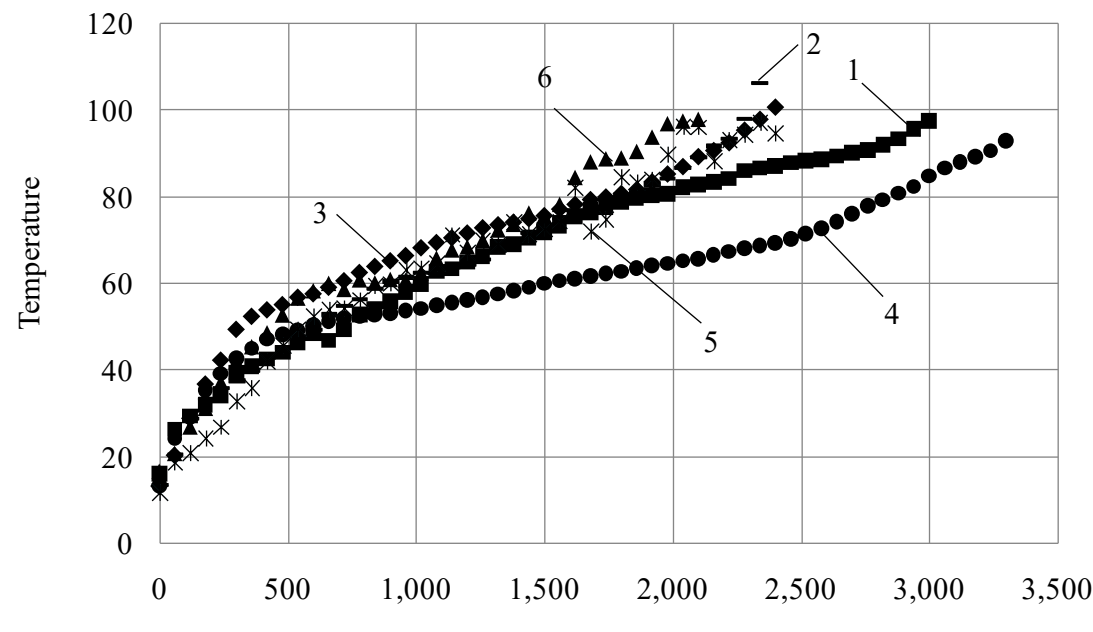

Time, $\mathrm{s}$

Fig. 10. Thermograms of slices from vegetables and fruits, $N=8.75 \mathrm{~kW} / \mathrm{m}^{2}$ : 1 - beetroot; 2 - potatoes; 3 - pumpkin; 4 - onion; 5 - carrot; 6 -apple

After testing the adequacy of the resulting model (2) and comparing the estimated and experimental data (Fig. 11), it was determined that the resulting model corresponded to experimental data with a difference of $15 \%$, which is a significant result of our study confirming the effectiveness and accuracy of the resulting equation. The range of change in the defining similarity numbers is $9.4 \cdot 10^{-7} \leq B u \leq 5.6 \cdot 10^{-6}$, $0.75 \leq H \leq 0.3$. 


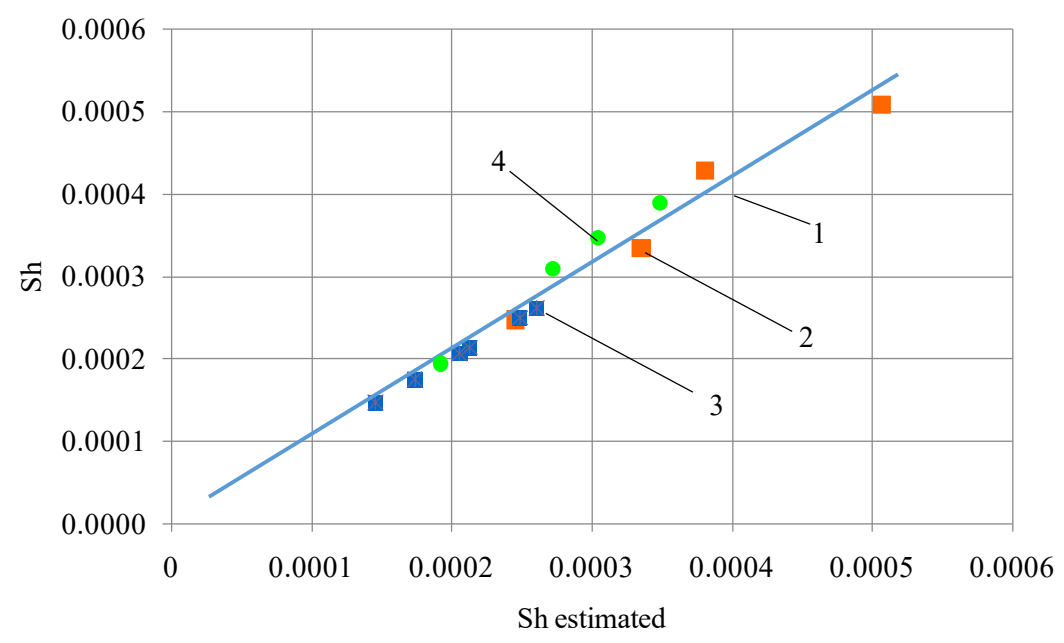

Fig. 11. Correlation field for mathematical model (2): 1 - carrot; 2 - apple; 3 - pumpkin; 4 - onion
Results from comparing the parameters of IR and UHF drying are given in Table 1.

Table 1

Effect of product type and radiation on drying parameters

\begin{tabular}{|c|c|c|c|c|c|}
\hline \multirow{2}{*}{$\begin{array}{c}\text { No. of } \\
\text { entry }\end{array}$} & \multirow{2}{*}{ product } & \multicolumn{2}{|c|}{$\begin{array}{c}\text { Drying rate, } \\
\text { g/min }\end{array}$} & \multicolumn{2}{c|}{$\begin{array}{c}\text { Process } \\
\text { duration, s }\end{array}$} \\
\cline { 3 - 6 } & IR & UHF & IR & UHF \\
\hline 1 & onion & 0.8 & 1.8 & 720 & 300 \\
\hline 2 & carrot & 1.1 & 2.5 & 540 & 260 \\
\hline 3 & potatoes & 1.15 & 2.1 & 520 & 300 \\
\hline 4 & apple & 1.3 & 2.2 & 490 & 280 \\
\hline 5 & $\begin{array}{c}\text { pump- } \\
\text { kin }\end{array}$ & 1.5 & 2.3 & 480 & 275 \\
\hline
\end{tabular}

\section{3. Comparison of experimental data} on the infrared and ultra-high-frequency drying of fruit and vegetable slices

The reported results on the kinetics and energy intensity of IR drying were compared with experiments under conditions of UHF radiation (Fig. 12). At a radiation power of $6 \mathrm{~kW} / \mathrm{m}^{2}$, we studied the drying kinetics of a layer of carrot, apple, and onion slices. Dimensions of the slices are: $3 \mathrm{~mm}$ thick, $0.025 \mathrm{~m}$ in radius. The cassette was loaded with $50 \mathrm{~g}$ of a product.

The UHF drying rate lines for fruits and vegetables varied in the range of $1.95 \ldots 2.25 \mathrm{~g} / \mathrm{min}$ of removed moisture. Constant drying rate is observed on average up to the moisture content of $23-28 \%$, after which there is a decrease in rate.

The temperatures of the product turned out to be lower than those in experiments with IR generators (Fig. 13).

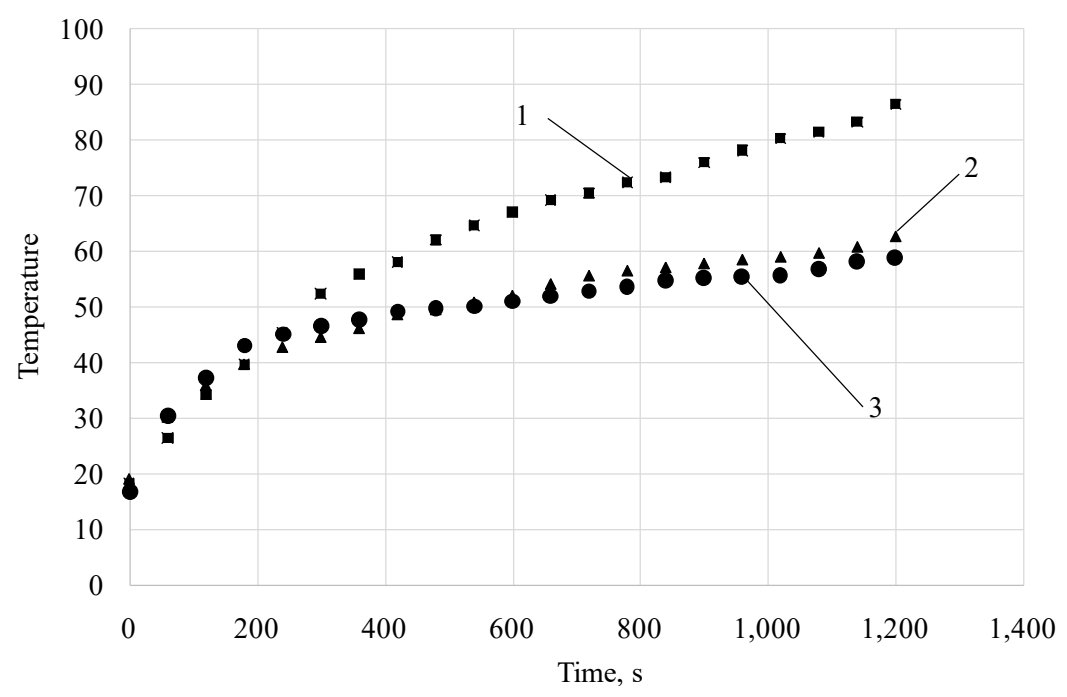

Fig. 13. Thermograms of UHF drying of slices from fruits and vegetables: 1 - carrot; 2 - apple; 3 - onion

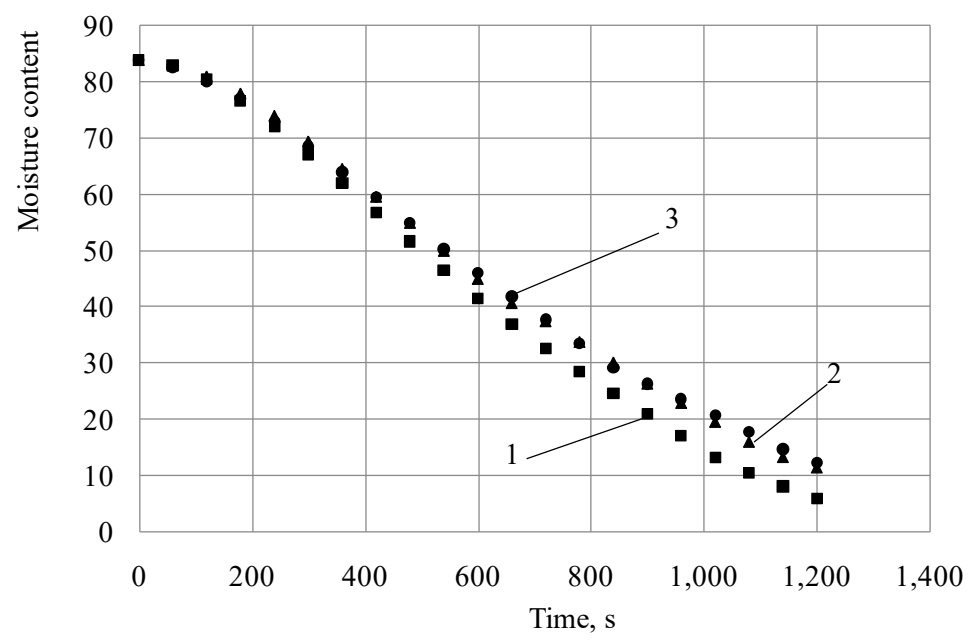

Fig. 12. Kinetics of the UHF drying process of fruit and vegetable slices: 1 - carrot; 2 - apple; 3 - onion
The UHF drying of fruit and vegetable slices at the same value of specific power requires almost 2 times less time for the process and is characterized by a 2-time higher values of drying rate.

When comparing quality indicators for slices obtained when using the UHF and IR drying (Table 2), there is no dependence of benefits of a separate technique. For example, in carrots, the highest content of $45 \mathrm{mg} / 100 \mathrm{~g}$ of $\beta$-carotene was determined in samples obtained from UHF drying; in samples after IR drying, the vitamin $\mathrm{C}$ content was $44.7 \mathrm{mg} / 100 \mathrm{~g}$.

Analysis of the data given in Table 2 reveals that all samples of raw materials dried using a convection technique are characterized by a lower level of values for all examined indicators in comparison with those dried in the IR and UHF dryers. 
Table 2

Effect of drying technique on slice quality parameters

\begin{tabular}{|c|c|c|c|c|c|}
\hline $\begin{array}{c}\text { Raw } \\
\text { material }\end{array}$ & Indicator title & $\begin{array}{c}\text { Fresh } \\
\text { raw } \\
\text { mate- } \\
\text { rial }\end{array}$ & $\begin{array}{c}\text { Con- } \\
\text { vection }\end{array}$ & IR & UHF \\
\hline \multirow{2}{*}{ Carrot } & $\begin{array}{l}\text { Mass share of } \\
\text { moisture, } \%\end{array}$ & 85.7 & \multicolumn{3}{|c|}{12} \\
\hline & $\begin{array}{c}\text { Mass share of } \\
\beta \text {-carotene, } \mathrm{mg} / 100 \mathrm{~g}\end{array}$ & 8.6 & 41.3 & 44.7 & 45.0 \\
\hline \multirow{2}{*}{$\begin{array}{l}\text { Pump- } \\
\text { kin }\end{array}$} & $\begin{array}{l}\text { Mass share of } \\
\text { moisture, \% }\end{array}$ & 86 & \multicolumn{3}{|c|}{10.1} \\
\hline & $\begin{array}{c}\text { Mass share of } \\
\beta \text {-carotene, } \mathrm{mg} / 100 \mathrm{~g}\end{array}$ & 8 & 38.39 & 41.72 & 41.94 \\
\hline \multirow{3}{*}{ Apple } & $\begin{array}{c}\text { Mass share of } \\
\text { moisture, } \%\end{array}$ & 85 & \multicolumn{3}{|c|}{10.7} \\
\hline & $\begin{array}{c}\text { Mass share of } \\
\text { vitamin } \mathrm{C}, \mathrm{mg} / 100 \mathrm{~g}\end{array}$ & 11.2 & 22.7 & 26.1 & 24.8 \\
\hline & $\begin{array}{c}\text { Mass share of } \\
\text { phenolic substances, } \\
\text { mg/100 g }\end{array}$ & 180 & 626 & 679 & 650 \\
\hline \multirow{2}{*}{ Onion } & $\begin{array}{c}\text { Mass share of } \\
\text { moisture, \% }\end{array}$ & 86 & \multicolumn{3}{|c|}{10.1} \\
\hline & $\begin{array}{c}\text { Mass share of vitamin } \\
\mathrm{C}, \mathrm{mg} / 100 \mathrm{~g}\end{array}$ & 10 & 20.79 & 24.01 & 21.82 \\
\hline
\end{tabular}

5. 4. Results on the degree to which the concentration of non-water components in a microwave evaporating plant is increased

The degree of increase in the concentration of non-water components in MEP (Fig 14) has been experimentally determined.

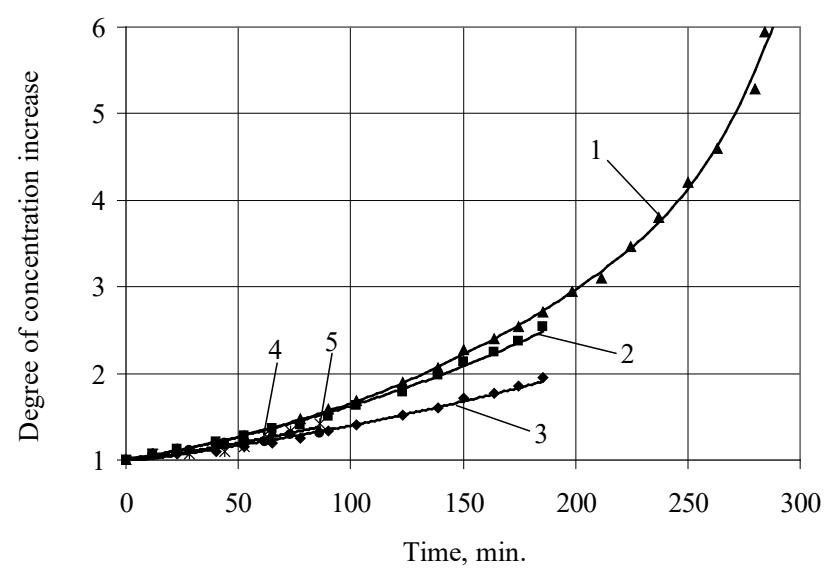

Fig. 14. Kinetics of increasing the concentration of watercontaining systems: 1 - apple juice, 2 - milk, 3 - tomato paste, 4 - oak wood-water, 5 -sand-water

Approximating curves were obtained using the method of the smallest squares.

When evaporating in a MEP, the degree of increase in the concentration (Fig. 14) of non-water components has the same trend for all systems and is not much different, especially in the initial period. The lowest intensity of steam formation was demonstrated by tomato paste (Fig. 14). The concentration of apple juice was increased by 6 times (Fig. 14). The main factor that determines the intensity of the formation of the steam phase in MEP is the power of electromagnetic energy generators.

\section{Discussion of results of studying the operation of innovative equipment for integrated processing of food raw materials}

When modeling condensate movement within an RTS, a large amount of condensate accumulates in the tubes closest to the vaporizer (Fig. 3), which is due to the separation of eth$\mathrm{yl}$ alcohol fractions, which is used as a working body.

At rotational frequencies of $n=0.1 \ldots 0.3 \mathrm{~s}^{-1}$ (Fig. 3), the estimated Froude number, obtained using the model developed in paper [9], is $F r<1$, and condensate freely returns to the vaporizer, both at vertical position and at the RTS inclination. At a rotation frequency of $1.8 \mathrm{~s}^{-1}$ and a condenser inclination angle of $\gamma=20^{\circ}$ the estimated number is $F r>1$, condensate is locked by the centrifugal force. All this confirms the reliability of the model developed.

When analyzing the kinetic curves of drying slices in the IR dryer, it was revealed that the temperatures of different kinds of vegetables and fruits have almost the same growth pattern (Fig. 10). This is because the temperature of the process is largely determined by the height of the product layer. The thickness of the layer in our experiments was $0.003 \mathrm{~m}$, which almost negates the effect of the thermal physical properties of the product on the heating dynamics.

For each product, the drying rate is constant (Fig. 9) to the moisture content of 20-23\%, after which the drying rate slows down. This is due to the achievement of critical humidity, which corresponds to the onset of the removal of hygroscopic moisture.

Comparison of experimental data on the IR and UHF drying shows that the product temperatures at UHF drying (Fig. 13), at the same power supplied $\left(6 \mathrm{~kW} / \mathrm{m}^{2}\right)$, were lower, and the rate of drying is almost twice larger ( Table 1). This is because the UHF field penetrates to a greater depth, initiating a barodiffusion effect, which leads to an increase in the rate of evaporation of water from the surface.

Our analysis of evaporation data in the MEP revealed that the lowest intensity of vaporization was demonstrated by tomato paste (Fig. 14). This is due to that the bonding energy for water in this system is higher than that of other solutions.

Compared to the results by other researchers in the field of TT, RTS, we conducted an experimental study by visualizing theprocess of hydrodynamicsusingaglass model, with the RTS branched structures applied (Fig. 3, 4). In contrast to [6, 7], we used sloped RTS at lower rotational frequencies $\left(0 \ldots 2 \mathrm{~s}^{-1}\right)$.

Unlike previous studies [13,14], we have obtained data on the IR drying kinetics for new products and the effect of mode parameters on the process. The model in similarity numbers (2) makes it possible to analyze the physical essence of the process, as well as employ fewer parameters in experimental modeling.

The concentration of apple juice in the MEP was increased by 6 times (Fig. 14). And this is basically impossible in traditional steaming machines.

The constraint on using the results is that the developed model (2) operates only in the range of change in the defining similarity numbers $\left(9.4 \times 10^{-7} \leq B u \leq 5.6 \times 10^{-6}, 0.75 \leq H \leq 0.3\right)$.

The shortcomings of studying the IR drying include the lack of confirmed data on the depth of radiation penetration into the material layer, the need to justify the rational thickness of the layer, the need to substantiate the optimal distance from an emitter.

The limitation for applying results on the IR drying is the lack of product movement, which significantly reduces per- 
formance of the installation. It should also be noted for MEP that the development of specialized microwave equipment is necessary to implement the process on an industrial scale. To this end, it is worth continuing experimental research.

\section{Conclusions}

1. Our study on the modeling of hydrodynamics in RTS has shown that for an auger RTS the return of condensate to the vaporizer, the internal heat exchange would be most effective at the condenser inclination angle of $37 \ldots 45^{\circ}$. For a branched condenser (Fig. 3), at the rotation frequency of $1.8 \mathrm{~s}^{-1}$ and inclination angle $\mathrm{g}=20^{\circ}$, condensate is locked by a centrifugal force in the condenser branch pipes. The results obtained will be used to develop methods for calculating and optimizing devices based on RTS.
2. Our study of the IR drying process has demonstrated that the determining effect on the process is exerted by the power supplied and thickness of the product layer. This is also confirmed by the analysis of the resulting model (2). The exponent with Bu number (it also includes power) is 1.8, the inverse dependence on the parametric complex of layer thickness $(\mathrm{H})$ exponent -1.28 .

3. Comparison of data on the IR and UHF drying of fruit and vegetable slices shows that with the same value of specific power $\left(6 \mathrm{~kW} / \mathrm{m}^{2}\right)$ the UHF drying requires 2 times less time for the process and is characterized by a 2-time larger values for drying rate (Table 1).

4. The study conducted into the evaporation of solutions in MEP has demonstrated that the lowest intensity of vapor formation was demonstrated by tomato paste (Fig. 14). The concentration of apple juice was increased by 6 times (Fig. 14).

\section{References}

1. Pereira, R. N., Vicente, A. A. (2010). Environmental impact of novel thermal and non-thermal technologies in food processing. Food Research International, 43 (7), 1936-1943. doi: https://doi.org/10.1016/j.foodres.2009.09.013

2. Hrovatin, N., Dolšak, N., Zorić, J. (2016). Factors impacting investments in energy efficiency and clean technologies: empirical evidence from Slovenian manufacturing firms. Journal of Cleaner Production, 127, 475-486. doi: https://doi.org/10.1016/ j.jclepro.2016.04.039

3. Meyers, S., Schmitt, B., Chester-Jones, M., Sturm, B. (2016). Energy efficiency, carbon emissions, and measures towards their improvement in the food and beverage sector for six European countries. Energy, 104, 266-283. doi: https://doi.org/10.1016/ j.energy.2016.03.117

4. Duan, L., Qi, C., Ling, X., Peng, H. (2018). The contact heat transfer between the heating plate and granular materials in rotary heat exchanger under overloaded condition. Results in Physics, 8, 600-609. doi: https://doi.org/10.1016/j.rinp.2017.12.018

5. Duan, L., Cao, Z., Yao, G., Ling, X., Peng, H. (2017). Visual experimental study on residence time of particle in plate rotary heat exchanger. Applied Thermal Engineering, 111, 213-222. doi: https://doi.org/10.1016/j.applthermaleng.2016.09.087

6. Kamal, M. M., Amer, I., Aboelnasr, M. (2010). Rotating Heat Pipe Performance with Internal Wire Mesh Screens. Proceedings of the Institution of Mechanical Engineers, Part A: Journal of Power and Energy, 224 (7), 993-1005. doi: https:// doi.org/10.1243/09576509jpe962

7. Hassan, H., Harmand, S. (2017). An experimental work on the effect of the radius of rotation on the performance of revolving heat pipe (RVHP). Applied Thermal Engineering, 123, 537-545. doi: https://doi.org/10.1016/j.applthermaleng.2017.05.133

8. Jouhara, H., Chauhan, A., Nannou, T., Almahmoud, S., Delpech, B., Wrobel, L. C. (2017). Heat pipe based systems - Advances and applications. Energy, 128, 729-754. doi: https://doi.org/10.1016/j.energy.2017.04.028

9. Burdo, O. G., Bezbah, I. V. (2008). Rotating heat pipes in devices for heat treatment of the food-stuffs. Applied Thermal Engineering, 28 (4), 341-343. doi: https://doi.org/10.1016/j.applthermaleng.2006.02.021

10. Burdo, O. G., Burdo, A. C., Sirotyuk, I. V., Pour, D. S. (2017). Technologies of Selective Energy Supply at Evaporation of Food Solutes. Problemele energeticii regionale, 1 (33), 100-109. Available at: http://journal.ie.asm.md/assets/files/12_01_33_2017.pdf

11. Burdo, O. G. (2010). Evolyutsiya sushil'nyh ustanovok. Odessa: Poligraf, 368.

12. Wang, Q., Li, S., Han, X., Ni, Y., Zhao, D., Hao, J. (2019). Quality evaluation and drying kinetics of shitake mushrooms dried by hot air, infrared and intermittent microwave-assisted drying methods. LWT, 107, 236-242. doi: https://doi.org/10.1016/ j.lwt.2019.03.020

13. Salehi, F., Kashaninejad, M. (2018). Modeling of moisture loss kinetics and color changes in the surface of lemon slice during the combined infrared-vacuum drying. Information Processing in Agriculture, 5 (4), 516-523. doi: https://doi.org/10.1016/ j.inpa.2018.05.006

14. Younis, M., Abdelkarim, D., Zein El-Abdein, A. (2018). Kinetics and mathematical modeling of infrared thin-layer drying of garlic slices. Saudi Journal of Biological Sciences, 25 (2), 332-338. doi: https://doi.org/10.1016/j.sjbs.2017.06.011 